\section{- Abuso de Álcool na Gestação e a Saúde Física e Psicológica do Bebê: Um Olhar Psicanalítico}

\section{Abuse of Alcohol during Pregnancy and The Physical and Psychological Health of The Baby: A Psychoanalytic View}

\section{Resumo}

O presente estudo tem como objetivo pesquisar o consumo excessivo de álcool pelas gestantes e o comportamento dos bebês recém-nascidos, abordando consequências fisiológicas e psicológicas, visando também o tratamento e a prevenção. Trata-se de uma pesquisa de cunho bibliográfico, que investigou a relação entre o consumo de álcool pelas gestantes e a saúde física e psicológica dos bebês, tendo como referência teórica estudos psicanalíticos da relação mãe-bebê.

Palavras-Chave: Abuso de álcool. Gravidez. Psicanálise.

\section{Abstract}

The present study aims to investigate the excessive consumption of alcohol by pregnant women and the behavior of newborn babies, addressing physiological and psychological consequences, as well as treatment and prevention. This is a bibliographical research that will investigate the relationship between alcohol consumption by pregnant women and the physical and psychological health of the babies, having as theoretical reference psychoanalytic studies of the mother-baby relationship.

Keywords: Alcohol abuse. Pregnancy. Psychoanalysis.

\section{Introdução}

A relação simbiótica entre mãe e bebê, principalmente na gestação e no primeiro ano de vida, é muito significativa para as fases seguintes
Prof. ${ }^{a}$ Dr. ${ }^{a}$ Veridiana

Canezin Guimarães

Psicologia - Centro

Universitário do Distrito

Federal - UDF

Prof. ${ }^{a}$ Regiane

Ribeiro

Psicologia - Centro

Universitário do Distrito

Federal - UDF

Prof. ${ }^{a}$ Tuanne

Sousa

Psicologia - Centro

Universitário do Distrito

Federal - UDF

Prof. ${ }^{a}$ Audinéia

Pereira

Psicologia - Centro

Universitário do Distrito Federal - UDF 
na vida da criança, e caso seja uma relação de abusos e não preocupação com a saúde do bebê/feto, isso pode gerar consequências graves.

A teoria psicanalítica, de modo geral, traz estudos e reflexões importantes sobre a relação mãe-bebê. Winnicott (1990) acreditava que, para compreendermos o desenvolvimento humano, seria necessário partirmos de uma observação do bebê desde o período mais primitivo, muito antes da experiência do nascimento, para analisarmos a relação do bebê com sua mãe a partir de então, sem descartar a hipótese de que tudo o que é vivido no útero possui vital importância para o que se seguirá após o nascimento.

Nessa perspectiva, com o desenvolvimento do cérebro enquanto órgão em funcionamento, inicia-se o armazenamento de memórias corporais vividas ainda no útero, memórias essas que são reunidas para formar um ser humano, cujos movimentos do corpo e momentos da vida intrauterina não só são significativos, mas também registrados.

As primeiras relações materno-infantis, vão se constituir desde o nascimento do bebê até os primeiros anos de vida. É uma relação na qual o par mãe-bebê se comunicam pela conexão que é desenvolvida desde a concepção, no desenvolvimento do bebê no útero, no instante do nascimento, até a continuidade do desenvolvimento da criança.

A decorrência do consumo de bebidas alcoólicas pela gestante pode levar ao abortamento, natimortalidade e ao parto prematuro. Esses danos incluem alterações físicas, mentais, comportamentais e/ou de aprendizado, que podem ser irreversíveis e levar à dependência de álcool e de outras drogas, problemas mentais, dificuldades escolares e no trabalho, comportamento sexual inapropriado e problemas com a justiça.

Dessa forma, considera-se que o uso de bebidas alcoólicas pela mãe durante a gestação produz reverberações e potentes riscos para a saúde, tanto fisiológica quanto psicológica do bebê. Diante disso, foi observado que a vulnerabilidade social é um dos fatores de maior influência para tal acontecimento.
Há alguns fatores que se associam ao consumo de álcool pelas gestantes, como: a pouca idade, baixa escolaridade, baixa renda mensal, ausência do companheiro, contato com consumidores de álcool, ausência de planejamento familiar, início tardio do pré-natal e também a estrutura familiar.

Tais contextos são únicos e sua pluralidade eventualmente pode constituir um espaço que pode facilitar ou não o aparecimento de quadros cuja propensão ao uso de qualquer substância psicoativa traga identificação. Sabe-se que o álcool é uma droga lícita de fácil acesso e baixo custo, além disso, é conhecida por seus efeitos que oferecem socialização e tranquilidade o que a torna atrativa.

De acordo com Grinfeld e Segre (2009), o mecanismo de ação do álcool quando ingerido pela gestante faz com que a substância cruze a placenta via sangue materno, vai para o líquido amniótico e para o feto. Em cerca de uma hora, os níveis de etanol no sangue fetal e no líquido amniótico são equivalentes aos do sangue da grávida. Não se conhece uma dose segura na gestação, sendo aconselhável a abstinência alcoólica na gravidez.

O consumo de álcool durante a gestação é considerado um problema expressivo na saúde pública. Costumeiramente, as gestantes que possuem o hábito de consumir tal substância omitem essa informação durante a consulta médica. Além de tudo, esses profissionais, muitas vezes, não estão adequadamente treinados para coletar essa informação, o que dificulta o tratamento e intervenção (ELLIOTT; BOWER, 2008).

Fonseca, Silva e Otta (2010), ressaltam a importância do apoio social para a mãe, por proporcionar maior estrutura para exercer a função materna e a responsividade com o bebê. Além disso, esse apoio funciona como fator de prevenção e proteção para sintomas depressivos.

Ainda de acordo com Fonseca, Silva e Otta (2010), é importante reconhecer a gestação e - puerpério como momentos críticos para o desenvolvimento da criança, pelas alterações no psiquismo da mãe. Dessa forma, merecendo atenção especial dos responsáveis pelas políticas de saúde. 
De maneira psicológica, o abuso de álcool aponta para a insuficiência de algo. O álcool, por sua vez, cumpre o papel de completude. É nesse ponto que a psicanálise pode ser convocada, pois ela fornece instrumentos que elucidam a função da drogadição na singularidade do indivíduo. Assim fazendo, a psicanálise pode direcionar o olhar para aspectos que passariam despercebidos pela visão médica e pela perspectiva sociocultural.

Pensando nisso, é importante que o sofrimento da mãe alcoólica seja validado para que haja a possibilidade de reinventar espaços e ferramentas, o fortalecimento de rede de apoio e adesão aos tratamentos médicos, visando a recuperação e o impedimento da geração de novas crianças afetadas.

\section{Objetivo}

O presente estudo tem como objetivo investigar o consumo de álcool pelas gestantes e os comportamentos dos bebês recém-nascidos, abordando consequências fisiológicas e psicológicas, visando também refletir sobre o tratamento e a prevenção.

\section{Material e Métodos}

Foi realizada uma pesquisa qualitativa com levantamento bibliográfico da literatura psicológica e médica. Foram encontrados estudos em português e inglês, tendo como referencial teórico estudos psicanalíticos. Utilizou-se a plataforma SciELO e livros. As palavras-chave utilizadas foram: "feto", "recém-nascido ", "gestante", "álcool", "alcoolismo", "síndrome alcóolica fetal" e "transtornos relacionados ao uso de álcool".

\section{Resultados e Discussão}

Ao descobrir uma gravidez, normalmente a mulher muda sua orientação sobre si e sobre o mundo à sua volta, por mais que essas mudancas sejam baseadas na fisiologia, elas podem ser distorcidas segundo o comprometimento da saúde mental dessa mulher. Sem dúvida, as mudanças fisiológicas sensibilizam a mulher para as mudanças psicológicas (WINNICOTT, 1960).
A literatura tem descrito, ainda, a concomitância do consumo de álcool com a presença de problemas emocionais em gestantes. A mãe emocionalmente instável, não oferece o acolhimento, o afeto e a segurança que o recém-nascido requer, podendo desencadear na criança comprometimento de sua saúde física (MENDES; GALDEANO, 2006).

Em relação aos efeitos do álcool sobre o feto, a identificação de fatores de risco é de suma importância. Como não há estudos em larga escala sobre tais fatores e pelo fato de que os riscos estejam inter-relacionados e possam ser diferentes conforme as populações estudadas, torna-se difícil dispor de dados acurados a respeito (CHUDLEY, 2005).

Foi identificado que fatores como a pouca idade, menor escolaridade, baixa renda mensal, não coabitação com o companheiro, coabitação com consumidores de álcool, tabagismo, uso de drogas ilícitas, gravidez não planejada e início tardio do pré-natal associam-se ao consumo de álcool pelas gestantes (MESQUITA; SEGRE, 2009).

De acordo com May (2008), estudos revelam que mães alcoolistas, cujos filhos apresentam sinais de terem sofrido os efeitos do álcool na vida intrauterina, possuem idade materna entre 21-25 anos. Além disso, é comum que haja antecedentes familiares de dependência do álcool. Sobre o uso do álcool por adolescentes, a explicação se dá pela fase que é caracterizada pela cobrança de comportamentos semelhantes aos de adultos e pelo desejo de fazer parte de um grupo (FISHMAN, 1988).

Observando a obra de Freud sobre o mal-estar na civilização, é notável a vinculação entre humanidade e civilização, em que o imperativo de gozo faz com que os sujeitos recorram à droga como um amortecedor de preocupações. Freud considera que a civilização é uma fonte de desconforto do sujeito em sua existência (FREUD, 1930).

Sobre as contribuições da psicanálise, para Figueiredo e Minerbo (2006), toda investigação psicanalítica tem efeito terapêutico. Isso se refere a busca pela compreensão dos sujeitos sobre as suas experiências com o abuso de 
álcool e a ressignificação dessa experiência, o que facilita a intervenção visando o alívio psíquico e a mudança de hábitos.

Os estudos apontaram para a necessidade de melhorias na assistência à saúde da mulher em todo seu período reprodutivo. A falha na prevenção do abuso de álcool na gestação ocorre por diversas razões como, por exemplo, na ausência de anamnese detalhada, o que, muitas vezes, se deve pela vergonha em falar sobre o consumo no pré-natal e, até mesmo, a falta de conhecimento sobre os malefícios desse consumo.

\section{Conclusão}

Com base no entendimento de grande parte dos autores, conclui-se que a um interação mãe-bebê é importante. O consumo de bebida alcóolica durante a gestação leva ao comprometimento do processo de vinculação da mãe com seu filho. Tal processo pode ser influenciado por aspectos biopsicossociais uma vez que diferem de características pessoais, padrões de consumo, motivações para uso, perfil socioeconômico e cultural.

Como limitações do estudo notou-se a falta de pesquisas sobre o tema em língua portuguesa e, também, que ainda são escassas, em países subdesenvolvidos, pesquisas sobre o abuso de álcool na gestação e seus prejuízos ao recém-nascido. Esse estudo evidencia a necessidade de desenvolver pesquisas relacionadas ao tema apresentado, principalmente de cunho psicológico, para que haja contribuição para a qualidade de vida das mães e seus bebês.

Por fim, a pesquisa revela que há escassez de informação e conscientização para as usuárias sobre o consumo de bebidas alcoólicas na gestação, assim como seus prejuízos e efeitos. Observa-se a imprescindibilidade de políticas públicas a fim de esclarecer e orientar as gestantes para prevenir a instalação e evitar o agravamento dos danos causados pelo álcool.

\section{Referências}

CHUDLEY, A. E. et al. Fetal alcohol spectrum disorder: Canadian guidelines for diagnosis. Cmaj, v. 172, n. 5 suppl, p. S1-S21, 2005. DA SILVA MENDONÇA, J. R. A droga como um recurso ao mal-estar na civilização. Psicologia em Revista, v. 17, n. 2, p. 240-260, 2011.

ELLIOTT, E. J.; BOWER, C. Alcohol and pregnancy: the pivotal role of the obstetrician. Australian and New Zealand Journal of Obstetrics and Gynaecology, v. 48, n. 3, p. 236-239, 2008.

FIGUEIREDO, L. C.; MINERBO, M. Pesquisa em psicanálise: algumas ideias e um exemplo. Jornal de Psicanálise, v. 39, n. 70, p. 257- 278, 2006.

FISHMAN, R. Alcoolismo (Coleção Tudo sobre drogas). São Paulo: Nova Cultural, 1988.

FONSECA, V. R. J. R. M.; SILVA, G. A. da; OTTA, E. Relação entre depressão pós-parto e disponibilidade emocional materna. Cadernos de saúde pública, v. 26, p. 738-746, 2010.

GRINFELD, H.; SEGRE, C. A. Recém-nascido de mãe alcoolista. Segre CA, Costa, v. 14, 2009.

MAY, P. A. et al. Maternal risk factors for fetal alcohol syndrome and partial fetal alcohol syndrome in South Africa: a third study. Alcoholism: Clinical and Experimental Research, v. 32, n. 5, p. 738-753, 2008.

MENDES, A. P. D.; GALDEANO, L. E. Percepção dos enfermeiros quanto aos fatores de risco para vínculo mãe-bebê prejudicado. Ciência, cuidado e saúde, v. 5, n. 3, p. 363-371, 2006.

MESQUITA, M. dos A.; SEGRE, C. A. de M. Freqüência dos efeitos do álcool no feto e padrão de consumo de bebidas alcoólicas pelas gestantes de maternidade pública da cidade de São Paulo. Journal of Human Growth and Development, v. 19, n. 1, p. 63-77, 2009.

WINNICOTT, D. W. Natureza humana. Rio de Janeiro: Imago, 1990.

O relacionamento inicial entre uma mãe e seu bebê. São Paulo: Martins Fontes, 1960.

A família e o desenvolvimento individual. São Paulo: Martins Fontes, 2011. 